\title{
Rota-Viral Diarrhoea Progressing to Necrotizing Enterocolitis in Twin Neonates
}

\author{
Roy $A^{1}$, Dogra $S^{2}$, Chatterjee $P^{3}$, Chattopadhya $A^{4}$
}

\begin{abstract}
We report late preterm twins who developed rota-viral diarrheal disease followed by necrotizing enterocolitis. Necrotizing enterocolitis had a fulminant course in both these neonates. Rota-viral infections in new-borns are reported to be mild or asymptomatic but in the above mentioned case, both the twins were severely affected leading to necrotizing enterocolitis. In the absence of risk factors, late preterm and term babies rarely develop Necrotizing Enterocolitis. We aim to highlight the importance of breast feeding through this case and also put forward the consideration for giving a birth dose of Rotaviral vaccination.
\end{abstract}

Key words: Rotavirus, Diarrhoea, Necrotizing enterocolitis, Rotavirus vaccine

\section{Introduction}

$\mathrm{R}^{\mathrm{s}}$ otavirus is a leading cause of diarrhoea in infants ${ }^{1}$. Strains that cause neonatal infections differ from those that infect older infants and are characterized by attenuated virulence. Necrotizing enterocolitis and pneumatosis intestinalis has rarely been described as its complications ${ }^{2}$. Necrotizing enterocolitis (NEC), an inflammatory bowel necrosis mostly affects premature infants with an incidence of $7 \%$ to $10 \%$ in very low birth weight (VLBW) infants. Incidence is inversely related to weight and gestational age and this is not a common entity in late preterm neonates in absence of risk factors.

\section{The Cases}

The twins were late preterms (35 weeks), appropriate for gestational age (AGA), male babies born to primi-gravida mother without any antenatal complication and were discharged on day five of life after an uneventful postnatal period. The babies were both breastfed and formula fed since birth. On day 15 of life both the babies developed loose stools which showed positive Rota-viral Antigen and they were managed conservatively with Total Parenteral nutrition (TPN) and antibiotics. However, after two days they started having abdominal distension, haemorrhagic nasogastric tube aspirates and few episodes of blood mixed stools and presented to our hospital.

\section{Twin 1:}

At initial assessment in our hospital, baby was sick with shallow breathing, grunting and poor perfusion. Baby had to be intubated
${ }^{1}$ Dr. Amrita Roy, Clinical Fellow, Department of Neonatology, John Radcliffe Hospitals, Oxford, UK, ${ }^{2} \mathrm{Dr}$. Shivani Dogra, Junior Consultant, Neonatology, Apollo Gleneagles Hospitals, Kolkata, India, ${ }^{3} \mathrm{Dr}$. Pallab Chatterjee, Consultant, Paediatrics and Neonatology, Apollo Gleneagles Hospitals, Kolkata, India. ${ }^{4}$ Dr. Anindya Chattopadhyay, Consultant, Paediatric Surgery, Apollo Gleneagles Hospitals, Kolkata, India.

\section{Address for correspondence}

Amrita Roy

E-mail: preences.amri3107@gmail.com

\section{How to cite}

Roy A, Dogra S, Chatterjee P, Chattopadhya A. Rota-Viral Diarrhoea Progressing to Necrotizing Enterocolitis in Twin Neonates. J Nepal Paediatr Soc 2017;37(2):204-206.

doi:http://dx.doi.org/10.3126/jnps.v37i2.17452

This work is licensed under a Creative Commons Attribution 3.0 License.

$$
\text { (c) (i) }
$$


and ventilated urgently along with fluid resuscitation, inotropes and empiric broad spectrum IV antibiotics. However, baby developed worsening abdominal distension which became tense and serial x-rays revealed a fixed intestinal loop. Exploratory laparotomy with resection of $15 \mathrm{~cm}$ ileum $(8 \mathrm{~cm}$ proximal to the ileocaecal valve) with double barrel ileostomy was done on day 31 of life and baby could be extubated on day second post-op.Baby had excessive stoma losses for which continuous NG feeds, lactose free formula were tried without much effect. lleostomy closure was done after four weeks in view of profuse stoma loss and poor weight gain. Baby was started on trophic feeds which were gradually advanced with few intermittent episodes of feed intolerance. Baby was finally started on elemental formula which the baby tolerated well and loose stools decreased. Baby was discharged on 86 day of life with stable weight gain and semi formed stools with a discharge weight of $1.998 \mathrm{~kg}$.

\section{Twin 2:}

On admission, the baby was found to be lethargic, hypoglycaemic, with abdominal distension and sluggish bowel sounds. He was started broad spectrum IV antibiotics and TPN through PICC line. Haematological parameters revealed raised Total leucocyte count (24300/cu.mm), low platelet count 15000/cu.mm. Straight X-ray abdomen showed thickened bowel walls. Acute inflammatory markers \& stool calprotectin were raised. Supportive measures in form of TPN, intravenous antibiotics and continuous nasogastric aspiration were continued after which the baby improved. After few episodes of feed intolerance, the baby started taking feeds well and was discharged on day 47 of life.

\section{Discussion}

Rota-viral diarrhoea is commonest cause of diarrhoea in infancy. Although Rotavirus (RV) infection in newborns is usually asymptomatic ${ }^{3,4}$, outbreaks have been reported associated with increased incidence of necrotizing enterocolitis (NEC) in preterm babies ${ }^{5}$. Sharma et al reported that out of $5.3 \%$ neonates who had NEC, $29 \%$ were rotavirus positive ${ }^{6}$. Rotavirus has been associated with NEC but the direct causal relationship has not been demonstrated. Both these

\section{References}

1. Bernstein DI. Rotavirus overview. Pediatr Infect Dis J 2009;28(suppl 3):S50-S53.

2. Capitanio MA, Greenberg SB. Pneumatosis intestinalis in two infants with rotavirus gastroenteritis. Pediatr Radiol 1991;21(5):361-2. neonates were asymptomatic and discharged home but later developed diarrhoea associated with rotavirus antigen positivity. The diarrhoea increased in severity and both the neonates developed abdominal distension, bleeding per rectum and other features of necrotizing enterocolitis.

Necrotizing enterocolitis is not a very common entity in late preterm neonates. Late preterm infants are more likely to develop NEC if they have other risk factors, including intrauterine growth retardation, polycythaemia, hypoglycaemia, sepsis, exchange transfusions or umbilical lines. However both these babies had a stable postnatal course and had no such risk factors. Borderline prematurity along with formula feeding and a Rota-viral infection could have contributed to the development of NEC

Available vaccines cannot be administered earlier than six weeks of age but they can be effective in prevention of nosocomial neonatal Rota-viral infection through herd immunity.In countries with high-mortality rates, monovalent rotavirus vaccines probably prevents $63 \%$ and pentavalent vaccine prevents $57 \%$ of severe rotavirus diarrhoea (Cochrane 2012) ${ }^{7}$. The concern of giving Rota-viral vaccine at birth is that the titres of circulating maternal antibodies in the infants and co administration of OPV may have a negative impact on the seroconversion rates. However a consideration may be given regarding the administration of an extra dose or a "Zero dose" similar to polio vaccine to improve serologic responses to future doses and it may also provide some protection. We also wish to emphasize the importance of breastfeeding to prevent this devastating complication in neonates.

\section{Conclusion}

Our twin babies had a stable postnatal course and had no risk factors for NEC other than being late preterms and being fed formula feeds. A subsequent Rota-viral infection could have triggered the development of NEC. Thus an extra "Zero dose" of Rota-viral vaccine at birth may give some protective immunity and may boost serologic responses to future doses. However, we cannot underestimate the importance of breastfeeding in preventing NEC.
3. Chrystie I. L., B. M. Totterdell, and J. E. Banatvala. Asymptomatic endemic rotavirus infections in the newborn. Lancet 1978;311(1075):1176-78.

4. Dunn SJ, Greenberg HB, Ward RL, et al. Serotypic and genotypic characterization of human serotype 10 rotaviruses from asymptomatic neonates. J Clin Microbiol 1993;31:165-169. 
5. Rotbart HA, Levin MJ, Yolken RH, Manchester DK, Jantzen J. An outbreak of rotavirusassociated neonatal necrotizing enterocolitis. J Pediatr1983;103(3):454-459.

6. Sharma R, Garrison RD, Tapas JJ, Mollitt DL, Pieper $P$ et al. Rotavirus-associated necrotizing enterocolitis: an insight into a potentially preventable disease? J Pediatr Surg 2004;39(3):453-45

7. Soares-Weiser $\mathrm{K}$ et al. Vaccines for preventing rotavirus diarrhoea: vaccines in use. Cochrane Database Systematic Review, 2012, 11:CD008521. 